\title{
Associations between serum 25(OH)D concentrations and prevalent asthma among children living in communities with differing levels of urbanization: a cross-sectional study
}

Suzanne L. Pollard ${ }^{1,2}$, John J. Lima ${ }^{3}$, Karina Romero ${ }^{1}$, Carla Tarazona-Meza ${ }^{4}$, Edward Mougey ${ }^{3}$, Katherine Tomaino ${ }^{2}$, Gary Malpartida-Guzmán ${ }^{4}$, Nadia N. Hansel', William Checkley ${ }^{1,2^{*}}$ and GASP Study Investigators

\begin{abstract}
Background: Prior evidence suggests that vitamin D deficiency may increase the risk of asthma and atopy and impair pulmonary function in children.

Methods: In this cross-sectional analysis nested in a case-control study, we analyzed serum 25(OH)D concentrations in 413 children with asthma and 471 children without asthma living in two geographically adjacent study communities (Pampas and Villa El Salvador). We measured total and antigen-specific IgE levels, pulmonary function, asthma control, and exhaled nitric oxide.
\end{abstract}

Results: Mean 25(OH)D concentrations were $25.2 \mathrm{ng} / \mathrm{mL}$ (SD 10.1) in children with asthma and $26.1 \mathrm{ng} / \mathrm{mL}$ (SD 13.7) in children without asthma $(p=0.28)$. Vitamin D deficiency $(25(\mathrm{OH}) \mathrm{D}<20 \mathrm{ng} / \mathrm{ml})$ was more common in Pampas than in Villa El Salvador (52.7\% vs. 10.5\%; $p<0.001)$. In the overall study population, a $10 \mathrm{ng} / \mathrm{ml}$ decrease in serum 25(OH)D concentrations was not significantly associated with odds of asthma (OR 1.09, 95\% Cl: 0.94 to 1.25). However, vitamin D deficiency was associated with a 1.6-fold increase in odds of asthma in the overall cohort (95\% Cl: 1.14 to 2.25). After stratifying by site, a $10 \mathrm{ng} / \mathrm{mL}$ decrease in serum 25(OH)D concentrations was associated with $18 \%$ higher odds of having asthma in Pampas ( $\mathrm{OR}=1.18,95 \% \mathrm{Cl} 1.02$ to 1.38), whereas there was no significant association between $25(\mathrm{OH}) \mathrm{D}$ concentrations and asthma in Villa El Salvador ( $\mathrm{OR}=0.95,95 \% \mathrm{Cl} 0.87$ to 1.05$)$. Combined data from these geographically adjacent populations suggests a possible threshold for the relationship between 25(OH)D levels and asthma at approximately $27.5 \mathrm{ng} / \mathrm{ml}$. Serum 25(OH)D concentrations were not clearly associated with asthma control, total serum IgE, atopy, or airway inflammation.

Conclusion: Serum $25(\mathrm{OH})$ D concentrations were inversely associated with asthma in one study community with a high prevalence of deficiency. Studies are needed to investigate a possible threshold 25(OH)D concentration after which higher vitamin D levels show no further benefit for asthma.

Keywords: Asthma, Pediatric asthma, Vitamin D, 25(OH)D, Nutrition, Urbanization

\footnotetext{
* Correspondence: wcheck11@jhmi.edu

'Division of Pulmonary and Critical Care, School of Medicine, Johns Hopkins

University, 1800 Orleans Ave, Suite 9121, Baltimore, USA

${ }^{2}$ Department of International Health, Bloomberg School of Public Health,

Johns Hopkins University, Baltimore, USA

Full list of author information is available at the end of the article
} 


\section{Background}

Asthma is a chronic lung disease characterized by airway inflammation, airflow limitation, bronchial hyperresponsiveness, and episodic wheeze and cough. An estimated 334 million individuals worldwide are currently living with asthma [1]. Asthma is the most common chronic disease in childhood, with an estimated $14 \%$ of children worldwide experiencing asthma symptoms in the previous year [1]. Recent research has focused on understanding the relationship between vitamin $\mathrm{D}$ deficiency and asthma and the potential benefits of vitamin D supplementation in improving a variety of asthmarelated outcomes.

Vitamin D may play a role in modulating risk and severity of asthma through its functions as an immune modulator, its role in lung development, and the effects of vitamin $\mathrm{D}$ deficiency on lung impairment and airway remodeling $[2,3]$. Vitamin D may also influence epigenetic programming in early life and may influence asthma severity and control through its anti-inflammatory properties and its potential role in reversing steroid resistance $[4,5]$. However, epidemiological studies on the relationship between vitamin D status and asthma, including cross-sectional and prospective studies, and randomized supplementation trials [6], have been conflicted.

Given the relative lack of large-scale studies of asthma and vitamin D in low- and middle-income countries, we sought to examine the relationship between vitamin $\mathrm{D}$ deficiency and prevalent asthma in a cohort of children and adolescents living in two peri-urban communities of Lima, Peru. An earlier study by our research group found an independent relationship between total serum $25(\mathrm{OH}) \mathrm{D}$ levels and asthma prevalence in children [7]. The current analysis was ancillary to a parent study of the role of genetic factors in modifying the relationship between air pollution and asthma. For the current analysis, we measured $25(\mathrm{OH}) \mathrm{D}$ levels in 413 children with asthma and 471 healthy controls, and we hypothesized that serum $25(\mathrm{OH}) \mathrm{D}$ concentrations would be inversely associated with odds of asthma, asthma severity, and markers of airway inflammation and allergy, and positively associated with pulmonary function.

\section{Methods}

\section{Study population and setting}

The study population was drawn from two communities, Pampas de San Juan de Miraflores (Pampas) and Villa El Salvador (Villa), located approximately $25 \mathrm{~km}$ south of the city center of Lima, Peru. Pampas and Villa have grown rapidly over the last two decades. As compared to Villa, a higher proportion of inhabitants in Pampas were born in the highlands, and a lower proportion were native to Lima. The two communities differ in age structure and socioeconomic status (SES), with Pampas being less urbanized, having a younger population, and having lower SES overall. However, the main economic activities between these two communities are similar. We chose to carry out this study in two communities to increase our recruitment pool of asthma cases. Annual average precipitation in Lima is less than $50 \mathrm{~mm}$ per year, and the city has high cloud cover 9 months of the year. A study conducted in 2010 by our group in 725 adolescents 13-15 years of age living in Pampas found that $22 \%$ of participants had lifetime wheeze, $12 \%$ had asthma symptoms, and $13 \%$ had a physician diagnosis of asthma [8]. This study was approved by the Institutional Review Boards at Johns Hopkins University School of Medicine, Baltimore, USA, and A.B. PRISMA in Lima, Peru.

\section{Study design}

This is an ancillary analysis of a subset of children enrolled in an unmatched case-control study carried out between July 2012 and March 2014. We enrolled children aged 9 to 19 years living in the two study communities. We excluded children with ocular, abdominal, or thoracic surgery in the past 3 months, hospitalization for cardiac reasons in the past 3 months, diagnosis or current treatment for tuberculosis, a chronic respiratory condition other than asthma, or were pregnant at enrollment. We recruited participants using household community census surveys. We identified and visited all potential asthma cases aged 9 to 19 years in the two communities using birthdate and a positive response to a census question identifying individuals with wheeze or use of asthma medications in the past 12 months, or a lifetime physician diagnosis of asthma. We identified children without asthma using a simple random sample of children aged 9 to 19 years in our census that responded negatively to all asthma-related census questions. We confirmed asthma status at enrollment and evaluated asthma severity in accordance with NAEPP-3 guidelines [9]. For this ancillary analysis, we defined children with asthma as having self- or parental-report of any occurrence of wheezing in the chest or any use of asthma medications in the past year. We defined children without asthma as no occurrence of self- or parentally-reported wheeze symptoms consistent with asthma in the past year and no use of asthma medications in the past year. Children with previous asthma were defined as children who had a physician diagnosis of asthma but had no symptoms or medication use related to asthma in the previous year; children with previous asthma were included as part of the non-asthma group for primary analyses. Per these definitions, we had a final enrollment of 258 and 248 children with asthma, and 374 and 297 without asthma, in Pampas and Villa, respectively. 


\section{Questionnaires}

We administered a baseline questionnaire, which included questions regarding demographic information, socioeconomic status, asthma medication use, history of allergic rhinitis and eczema, and smoking history.

\section{Clinical measurements}

We conducted spirometry at enrollment in all participants. We used a flow-based portable spirometer (SpiroPro, Jaeger/ERT, Hoechberg, Germany), obtaining at least three acceptable and reproducible spirometry maneuvers for a maximum of eight according to ATS/ ERS guidelines [10]. We calculated predicted values and Z-scores using multi-ethnic reference values derived by the Global Lung Health Initiative [11]. We measured Asthma Control Test (ACT) score using a validated questionnaire [12-14]. An ACT score $\geq 20$ is indicates controlled asthma, 16-19 is considered partially controlled, and $<16$ is considered uncontrolled [14]. We measured fractional exhaled nitric oxide (FeNO) using the handheld NIOXMINO (Aerocrine, Solna, Sweden). We used criteria derived by the World Health Organization to determine Body Mass Index (BMI)-forage Z-scores [15].

\section{Measurement of serum vitamin $D$ levels}

We collected one blood sample per participant using standard phlebotomy techniques. We separated and centrifuged samples within two hours of extraction and stored at $-80{ }^{\circ} \mathrm{C}$. We quantified serum $25(\mathrm{OH}) \mathrm{D}$ levels at the Analytical Laboratory at Nemours Children Health System, Jacksonville, FL using the ALPCO $25 \mathrm{OH}$ Vitamin D Total ELISA kit (ALPCO, Salem, NH). Body composition measures were determined through bioimpedance using the TANITA TBF-300 body composition analyzer (TANITA Corporation, Inc., Arlington Heights, IL). We measured both total serum Immunoglobulin E (IgE) and IgE specific antibodies to mixes of three common allergens (animal, mold, and dust mite) using the ImmunoCAP 250 (ThermoFisher Scientific, Kalamazoo, MI). An IgE level of $>0.1 \mathrm{kU} / \mathrm{L}$ indicated a positive IgE antibody response, and a positive response to any of the three mixes indicated atopy.

\section{Definition of vitamin D status}

We defined vitamin $\mathrm{D}$ deficiency as total serum 25(OH)D levels below $20 \mathrm{ng} / \mathrm{ml}$, and vitamin D insufficiency as a level between 20 and $30 \mathrm{ng} / \mathrm{ml}$ [16]. Atopy was defined as the presence of IgE antibody to mixes of one or more of three common allergens (mold, dust mite, and animal).

\section{Biostatistical methods}

We sought to determine associations between 25(OH)D serum concentrations and prevalent asthma and to determine associations between pulmonary function, FeNO, and allergy with 25(OH)D levels. For the parent study, our goal was to enroll 700 asthma cases and 700 controls. With this sample size, we could detect an odds ratio of 1.6 with a disease allele of frequency 0.1 with $80 \%$ power. We used multivariable logistic regressions to model the association between asthma and 25(OH)D and vitamin $\mathrm{D}$ deficiency after adjusting for season of blood draw, age, sex, BMI, and SES score, and conducted both combined analyses and stratified by atopy. We used multivariable linear regressions to model associations between total $25(\mathrm{OH}) \mathrm{D}$ levels and prebronchodilator forced expiratory volume in 1 second $\left(\mathrm{FEV}_{1}\right)$, forced vital capacity (FVC), FeNO, total serum IgE, and ACT score. We used the chi-square test to compare proportions between children with and without asthma, and analysis of variance to compare means. We used a smoothing spline to visualize the relationship between unadjusted odds of asthma and serum 25(OH)D concentrations. We conducted a sensitivity analysis to determine if removing children with previous asthma (i.e. children with a previous asthma diagnosis but no current symptoms or medication use) affected the association between serum 25(OH)D concentrations and asthma (Additional file 1: Table S1). We generated a composite score for SES using Principal Component Analysis techniques. We used random forest methods to impute missing observations for SES ( $<10 \%$ of data). For all other analyses, participants with missing data were omitted. We conducted analyses in R (http://www.r-pro ject.org) and STATA 11 (Stata Corp., College Station, Texas).

\section{Results}

\section{Characteristics of the study population}

Of 1177 children enrolled, 884 (413 with asthma, 471 without asthma) had serum available for analysis of 25(OH)D levels. There were no differences in age (13.4 vs. 13.5 years, $p=0.48)$, sex ( $50.9 \%$ vs. $53.4 \%$ male, $p=$ $0.45)$, atopy $(69.7 \%$ vs. $79.0 \%$ with atopy, $p=0.39)$, prebronchodilator $\mathrm{FEV}_{1} \mathrm{Z}$-score (1.3 vs. 1.4, $p=0.57$ ), or body mass index (21.9 vs. $21.5, p=0.13)$ between individuals with and without a blood sample, respectively. There was a significant difference in the proportion with asthma $(46.7 \%$ vs. $31.7 \%, p<0.001)$ in children with and without a blood sample. Among the 884 children, mean age at enrollment was 13.4 years $(\mathrm{SD}=2.65), 53.4 \%$ were boys, and $52.6 \%$ lived in Pampas. There were differences in SES indicators between study communities, but the proportion of children with asthma was similar. 
We summarized baseline characteristics of children with asthma as compared to controls (Table 1). Children with asthma had higher BMI and BMI-for-age Z-score. They also differed by indicators of SES and calendar quarter of blood draw. Asthma was associated with a lower pre-bronchodilator $\mathrm{FEV}_{1} \mathrm{Z}$-score and $\mathrm{FEV}_{1} / \mathrm{FVC}$ Z-score, but not with pre-bronchodilator FVC Z-score. Children with asthma had a higher prevalence of atopy, self-reported allergy and eczema, parental history of asthma and allergic rhinitis, and FeNO levels than

Table 1 Participant characteristics among children with and without asthma

\begin{tabular}{|c|c|c|c|}
\hline & Children with Asthma & Children without asthma & $p$-value \\
\hline Sample size & 413 & 471 & \\
\hline Lives in Pampas de San Juan, n (\%) & $374(55.7)$ & $258(51.0)$ & 0.11 \\
\hline \multicolumn{4}{|l|}{ Vitamin D Measures } \\
\hline Total 25(OH)D (ng/ml), mean (SD) & $25.2(10.1)$ & $26.1(13.7)$ & 0.28 \\
\hline \multicolumn{4}{|l|}{ Demographics } \\
\hline Age in years, mean (SD) & $13.9(2.65)$ & $14.0(2.77)$ & 0.43 \\
\hline n, (\%) boys & $234(56.7)$ & $238(50.5)$ & 0.07 \\
\hline \multicolumn{4}{|l|}{ Anthropometry } \\
\hline Height in cm, mean (SD) & $150.9(12.0)$ & $151.0(12.0)$ & 0.99 \\
\hline BMl in $\mathrm{kg} / \mathrm{m}^{2}$, mean (SD) & $22.2(4.23)$ & $21.7(4.07)$ & 0.03 \\
\hline BMI-for-age z-score, mean (SD) & $1.03(1.2)$ & $0.83(1.1)$ & 0.01 \\
\hline \multicolumn{4}{|l|}{ Socioeconomics, n (\%) } \\
\hline Maternal education $\geq 6$ years & $274(71.0)$ & $269(60.5)$ & 0.001 \\
\hline 6 or more household members & $200(51.6)$ & $232(51.6)$ & 0.99 \\
\hline SES Score & $0.243(1.68)$ & $-0.183(1.66)$ & $<0.001$ \\
\hline \multicolumn{4}{|l|}{ Smoking } \\
\hline Current smoker & $6(1.8)$ & $10(2.4)$ & 0.56 \\
\hline \multicolumn{4}{|l|}{ Pulmonary function, allergy, FeNO } \\
\hline Pre-BD FEV 1 z-score, mean (SD) & $1.08(1.40)$ & $1.55(1.16)$ & $<0.001$ \\
\hline Pre-BD FVC z-score, mean (SD) & $1.48(1.41)$ & $1.34(1.21)$ & 0.69 \\
\hline Pre-BD FEV $1 /$ FVC z-score, mean (SD) & $-0.355(-1.16)$ & $0.413(0.837)$ & $<0.001$ \\
\hline $\begin{array}{l}\text { Either parent with history of physician-diagnosed } \\
\text { asthma, n (\%) }\end{array}$ & $98(25.7)$ & $48(11.1)$ & $<0.001$ \\
\hline Atopy, n (\%) & $488(62.3)$ & $315(78.2)$ & $<0.001$ \\
\hline Pollen allergy (self-report), n (\%) & 38 (9.79) & $11(2.51)$ & $<0.001$ \\
\hline Animal dander allergy (self-report), n (\%) & $107(27.6)$ & $30(6.73)$ & $<0.001$ \\
\hline Ever having allergic rhinitis (self-report), n (\%) & $291(75.2)$ & $171(38.0)$ & $<0.001$ \\
\hline Either parent with history of allergic rhinitis (self-report), n (\%) & $124(32.6)$ & $88(20.2)$ & $<0.001$ \\
\hline Ever having eczema (self-report), n (\%) & $53(13.7)$ & $28(6.25)$ & $<0.001$ \\
\hline Either parent with history of eczema (self-report), n (\%) & $12(3.15)$ & $13(3.00)$ & 0.90 \\
\hline Fractional exhaled nitric oxide in ppb, mean(SD) & $34.3(32.9)$ & $20.0(21.4)$ & $<0.001$ \\
\hline \multicolumn{4}{|l|}{ Calendar quarter at time of blood draw, n, (\%) } \\
\hline January-March & $102(24.7)$ & $89(18.9)$ & $<0.001$ \\
\hline April-June & $13(3.15)$ & $9(1.91)$ & \\
\hline July-September & $73(17.7)$ & $4(0.85)$ & \\
\hline October-December & $225(54.5)$ & $369(78.3)$ & \\
\hline \multicolumn{4}{|c|}{ Mean daily frequency of vitamin D-rich food intake in 14 days prior to blood draw, mean (SD), $n=646$} \\
\hline Vitamin-D rich oily fish & $0.13(0.15)$ & $0.13(0.16)$ & 0.89 \\
\hline Vitamin-D fortified milk & $0.55(0.54)$ & $0.54(0.62)$ & 0.77 \\
\hline
\end{tabular}


controls. Mean total 25(OH)D concentrations were $25.7 \mathrm{ng} / \mathrm{ml}$ in all children enrolled in our study. Mean $25(\mathrm{OH}) \mathrm{D}$ concentration did not differ between participants with and without asthma (Table 1).

We summarized characteristics of children living in Pampas and Villa (Table 2). Children living in Pampas had significantly lower 25(OH)D concentrations and were slightly older. Children living in Villa had a significantly higher percentage of mothers with 6 or more years of education, as well as a higher composite SES score. Calendar quarter of blood draw differed between the two sites.

Table 2 Comparison of participant characteristics among children by study community

\begin{tabular}{|c|c|c|c|}
\hline & Pampas & Villa & $p$-value \\
\hline Sample size & 419 & 465 & \\
\hline Asthma status, n (\%) & $258(40.8)$ & $248(45.5)$ & 0.11 \\
\hline \multicolumn{4}{|l|}{ Vitamin D Measures } \\
\hline Total 25(OH)D (ng/ml), mean (SD) & $20.9(13.1)$ & $30.0(9.4)$ & $<0.001$ \\
\hline \multicolumn{4}{|l|}{ Demographics } \\
\hline Age in years, mean (SD) & $14.5(2.69)$ & $13.4(2.62)$ & $<0.001$ \\
\hline n, (\%) boys & $341(54.0)$ & $280(51.4)$ & 0.21 \\
\hline \multicolumn{4}{|l|}{ Anthropometry } \\
\hline Height in cm, mean (SD) & $151(12.2)$ & $151(11.8)$ & 0.74 \\
\hline $\mathrm{BMI}$ in $\mathrm{kg} / \mathrm{m}^{2}$, mean (SD) & $21.8(3.75)$ & $22.1(4.48)$ & 0.34 \\
\hline BMl-for-age z-score, mean (SD) & $0.840(1.1)$ & $1.00(1.22)$ & 0.04 \\
\hline \multicolumn{4}{|l|}{ Socioeconomics, n (\%) } \\
\hline Maternal education $\geq 6$ years & $210(52.9)$ & $333(76.7)$ & $<0.001$ \\
\hline 6 or more household members & $191(47.8)$ & $241(55.0)$ & 0.04 \\
\hline SES Score & $-0.684(1.57)$ & $0.793(1.45)$ & $<0.001$ \\
\hline \multicolumn{4}{|l|}{ Smoking } \\
\hline Current smoker & $11(3.06)$ & $5(1.23)$ & 0.08 \\
\hline \multicolumn{4}{|l|}{ Pulmonary function, allergy, FeNO } \\
\hline Pre-BD FEV ${ }_{1}$ z-score, mean (SD) & $1.36(1.27)$ & $1.31(1.31)$ & 0.57 \\
\hline Pre-BD FVC z-score, mean (SD) & $1.44(1.26)$ & $1.28(1.34)$ & 0.07 \\
\hline Pre-BD FEV 1 /FVC z-score, mean (SD) & $-0.0296(1.09)$ & $0.129(1.06)$ & 0.03 \\
\hline Either parent with history of physician-diagnosed asthma, n (\%) & $69(17.9)$ & $77(18.0)$ & 0.95 \\
\hline Atopy, n (\%) & $293(71.3)$ & $310(68.3)$ & 0.34 \\
\hline Pollen allergy (self-report), n (\%) & $27(6.94)$ & $22(5.02)$ & 0.24 \\
\hline Animal dander allergy (self-report), n (\%) & $71(17.9)$ & $66(15.1)$ & 0.27 \\
\hline Ever having allergic rhinitis (self-report), n (\%) & $229(57.5)$ & $233(53.2)$ & 0.21 \\
\hline Either parent with history of allergic rhinitis (self-report), n (\%) & $98(25.3)$ & $114(26.6)$ & 0.68 \\
\hline Ever having eczema (self-report), n (\%) & $56(14.1)$ & $25(5.71)$ & $<0.001$ \\
\hline Either parent with history of eczema (self-report), n (\%) & $18(4.63)$ & $7(1.64)$ & 0.01 \\
\hline Exhaled nitric oxide in ppb, mean(SD) & $29.6(30.8)$ & $23.2(24.6)$ & 0.001 \\
\hline \multicolumn{4}{|l|}{ Calendar quarter at time of blood draw, n, (\%) } \\
\hline January-March & 0 & $191(41.1)$ & $<0.001$ \\
\hline April-June & 0 & $22(4.73)$ & \\
\hline July-September & $77(18.4)$ & 0 & \\
\hline October-December & $342(81.6)$ & $252(54.2)$ & \\
\hline \multicolumn{4}{|c|}{ Mean daily frequency of vitamin D-rich food intake in 14 days prior to blood draw, mean (SD); $n=646$} \\
\hline Vitamin-D rich oily fish & $0.12(0.16)$ & $0.14(0.16)$ & 0.04 \\
\hline Vitamin-D fortified milk & $0.51(0.46)$ & $0.59(0.66)$ & 0.04 \\
\hline
\end{tabular}


Distributions of 25(OH)D concentrations, BMI-for-age Z-score, and SES score by study community

A higher proportion of the study population was vitamin $\mathrm{D}$ deficient in Pampas as compared to Villa (52.7\% vs. $10.5 \%, p<0.001$ ) (Fig. 1a). A lower proportion of individuals in Pampas as compared to Villa had BMI-forage Z-scores in the overweight or obese categories (39.1\% vs. $48.9 \%, p=0.01$ ) (Fig. 1b), and SES composite score was lower overall in Pampas vs. Villa $(-0.68$ vs. $0.79, p<0.001)$, indicating significantly higher SES in Villa (Fig. 1c).

\section{Relationship between total serum 25(OH)D concentrations and asthma}

We observed a U- or L-shaped association between unadjusted odds of asthma across 25(OH)D serum levels (Fig. 2). We observed an inverse relationship between odds of asthma and 25(OH)D levels at levels below approximately $27.5 \mathrm{ng} / \mathrm{ml}$, and we observed a positive relationship between odds of asthma and 25(OH)D levels above $27.5 \mathrm{ng} / \mathrm{ml}$. In the overall study population, a $10 \mathrm{ng} / \mathrm{ml}$ decrease in serum 25(OH)D concentrations was not significantly associated with odds of asthma (OR 1.09, 95\% CI: 0.94 to 1.25), after adjusting for season of blood draw, age, sex, BMI, atopy, site, and SES. However, vitamin D deficiency $(25(\mathrm{OH}) \mathrm{D}<20 \mathrm{ng} / \mathrm{ml})$ was associated with a 1.6-fold increase in odds of asthma in the overall cohort ( $95 \%$ CI: 1.14 to 2.25 ). Stratification showed important differences in this relationship by site. Specifically, in multivariable logistic regression, a $10 \mathrm{ng} /$ $\mathrm{ml}$ decrease in total serum 25(OH)D levels in children living in Pampas was associated with a significant $18 \%$ increase in odds of asthma when compared against healthy controls, after adjusting for season of blood draw, age, sex, BMI, atopy, and SES (Table 3). This relationship was no longer significant after stratifying by atopy, although it approached significance in children with atopy. Decreased serum 25(OH)D levels were associated with a non-significant decrease in odds of asthma in Villa. Similarly, vitamin D deficiency was associated with a 2.2-fold increase in odds of asthma in Pampas (95\% CI: 1.42 to $3.28, p<0.001$ ), whereas deficiency was associated a non-significant decrease in odds of asthma in Villa (OR $0.94,95 \%$ CI: 0.50 to $1.78, p=0.86$ ). In sensitivity analyses, removing children with previous asthma did not affect the direction of the associations or statistical significance (see Additional file 1: Table S1). However, the magnitude of the association increased upon removing previous cases in all but one association.

\section{Total serum 25(OH)D concentrations and pulmonary function}

Pre-bronchodilator $\mathrm{FEV}_{1} \mathrm{Z}$-scores did not differ between Pampas and Villa. However, pre-bronchodilator FVC Zscore was higher in Pampas when compared to Villa (1.4 vs. 1.3 SD, $p=0.03$ ). Pre-bronchodilator $\mathrm{FEV}_{1}$ and FVC Z-scores did not differ significantly between children with and without vitamin $\mathrm{D}$ deficiency. In adjusted analyses, pre-FEV 1 Z-score and pre-FVC Z-score were not significantly associated with $25(\mathrm{OH}) \mathrm{D}$ levels overall, or after stratifying by asthma status (Table 4).

\section{Total serum 25(OH)D concentrations and markers of inflammation, allergy, and asthma control}

In adjusted analyses, ACT score was not significantly associated with 25(OH)D levels. FeNO was significantly inversely associated with $25(\mathrm{OH}) \mathrm{D}$ levels in single variable analyses $(-0.03 \mathrm{ng} / \mathrm{ml}, 95 \% \mathrm{CI}-0.06$ to $-0.0004)$, but was not significantly associated in multivariable analyses $(-0.03 \mathrm{ng} / \mathrm{ml}, 95 \% \mathrm{CI}-0.06$ to 0.003). Finally, total serum IgE was not significantly associated with $25(\mathrm{OH}) \mathrm{D}$ levels in either unadjusted or adjusted analyses (Table 4).
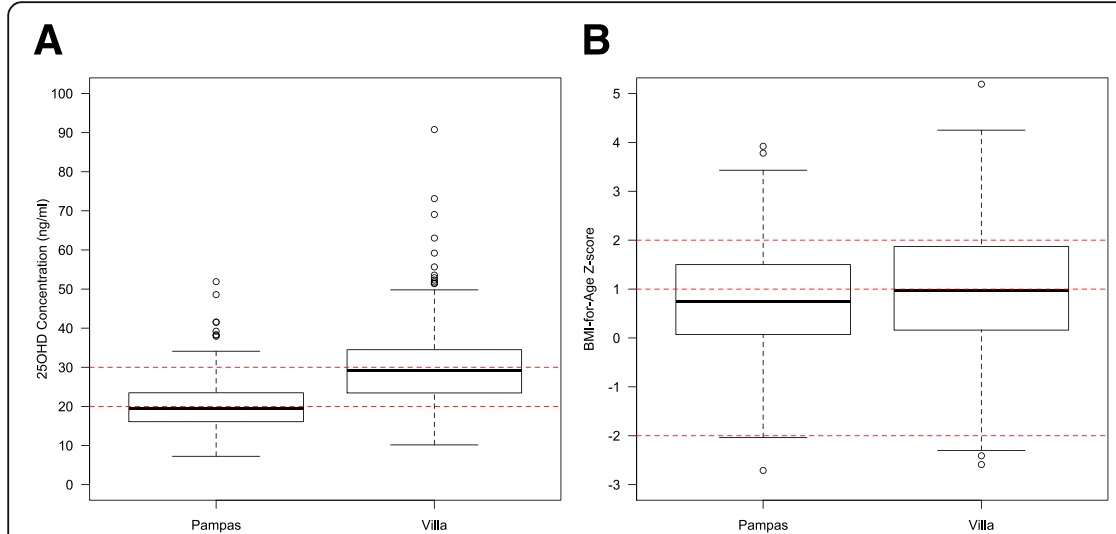

\section{C}

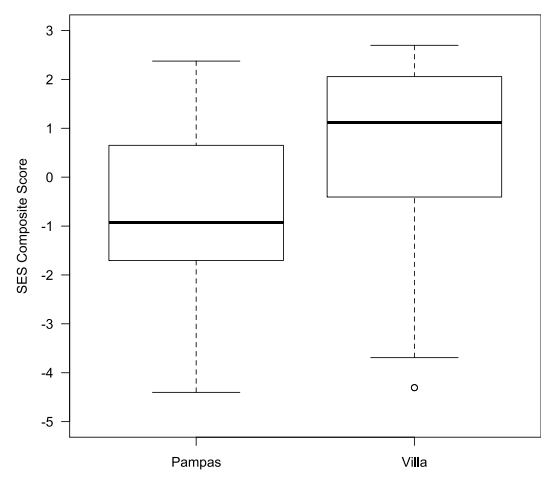

Fig. 1 Distributions of total 25(OH)D concentrations (a), BMI-for-Age Z-scores (b), SES Composite Score (c) between communities. Red horizontal dashed lines in 1a represent concentrations for vitamin D deficiency and insufficiency; dashed lines in $1 \mathrm{~b}$ represent cutoffs for underweight $(-2)$, overweight (+1), and obese (+2) 


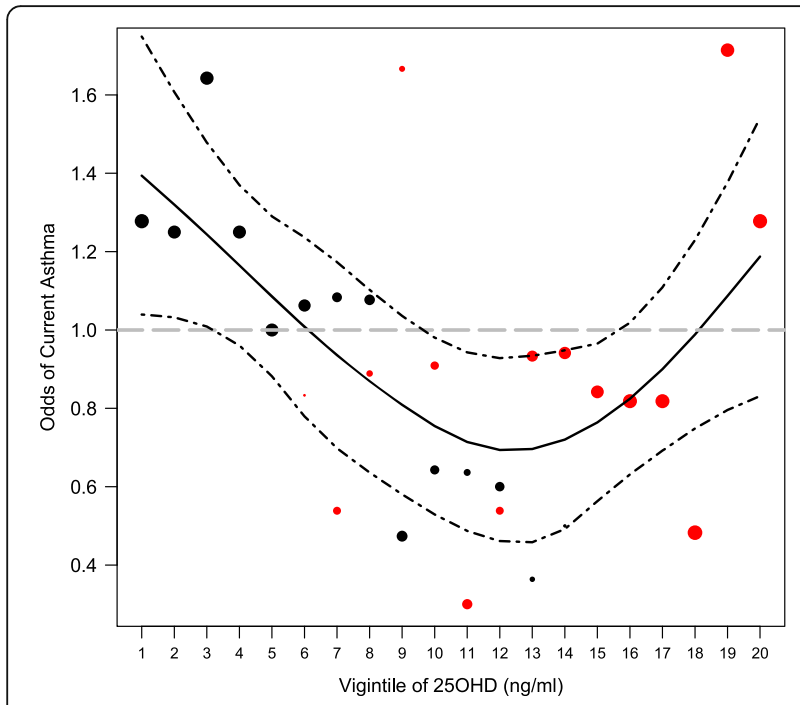

Fig. 2 Unadjusted odds of asthma for each vigintile of $25(\mathrm{OH}) \mathrm{D}$ concentrations. The solid line represents the lowess smoothed curve and the dashed lines represent confidence intervals for this curve. The black dots indicate the odds of asthma in Pampas de San Juan, and the red dots indicate the odds of asthma in Villa El Salvador. The size of the dot is proportional to the number of individuals included in calculation of the odds. Between vigintiles 1 through 13 (approximately $27.5 \mathrm{ng} / \mathrm{ml}$ ), we observed an inverse relationship between odds of asthma and 25(OH)D levels. Between vigintiles 13 and 20, we observed a positive relationship between odds of asthma and 25(OH)D levels

\section{Discussion}

In this study of 884 Peruvian children, we found that total serum 25(OH)D levels were not associated with odds of asthma in the combined study population, while vitamin $\mathrm{D}$ deficiency was independently associated with odds of asthma. However, stratification by study community revealed important differences. In Pampas, a decrease in $25(\mathrm{OH}) \mathrm{D}$ levels was significantly associated with prevalence of asthma. In Villa, we observed that increased $25(\mathrm{OH}) \mathrm{D}$ serum levels were associated with a non-significant increase in odds of asthma.

We found a significant association between 25(OH)D levels and odds of asthma in Pampas. These results replicate those found in a previous population-based study conducted in this community, where we found higher odds of asthma with lower $25(\mathrm{OH}) \mathrm{D}$ levels [7]. In the previous study, the prevalence of deficiency was similar to the prevalence in Pampas in the current study $(47 \%$ vs. $52.7 \%$ in previous vs. current study) [7]. Furthermore, like the current study, the relationship between $25(\mathrm{OH}) \mathrm{D}$ levels and asthma was stronger among children with atopy [7]. Thus, our results confirm previous observations in Pampas and suggest that the relationship between $25(\mathrm{OH}) \mathrm{D}$ serum levels and asthma may be most relevant among children with allergic asthma. The sample size for children without atopy was smaller than those with atopy, which could explain the lack of statistical significance in this analysis. Future studies should consider stratification by atopy to capture differences among individuals with the allergic phenotype.

In Villa, we did not observe a significant relationship between asthma and $25(\mathrm{OH}) \mathrm{D}$ concentrations. Given that the prevalence of vitamin D deficiency was far lower in Villa, our results may indicate that vitamin D deficiency and prevalent asthma are more strongly associated in individuals with more severe deficiency. The populations of Pampas and Villa, while geographically adjacent, differ in several factors that may help explain the differing associations between communities and the different prevalences of deficiency. Villa is more urbanized than Pampas, with more major roadways and commercial activity and areas with higher population density. Furthermore, our data indicate that the population of Villa has higher overall SES and differing age structures, with the percentage of individuals over age 65 being over two times higher in Villa $(\sim 7 \%)$ vs. Pampas $(\sim 3 \%)$. Although we adjusted for SES, there may be lifestyle factors related to urbanization that influence vitamin D status not accounted for in our models. Nutritional factors such as magnesium and calcium intake have been hypothesized to influence vitamin D absorption. Data from a food frequency questionnaire in a subset of 646 children in our study show that in Villa, children consumed a higher mean daily frequency of vitamin D-rich oily fish and fortified milk in the 2 weeks prior to blood draw (Table 2), indicating that nutritional factors were likely important drivers of the differences in $25(\mathrm{OH}) \mathrm{D}$ distributions between communities. Physical activity levels also may differ between the two communities,

Table 3 Multivariable logistic regression analysis of the association between $25-\mathrm{OH}$ vitamin D levels and asthma among 884 children and adolescents in Lima, Peru

\begin{tabular}{llll}
\hline & \multicolumn{2}{l}{ Adjusted $^{\mathrm{a}}$ ORs $(95 \% \mathrm{Cl})$ with total serum 25(OH)D levels (per $10 \mathrm{ng} / \mathrm{ml}$ decrease $)$} \\
\cline { 2 - 4 } & Overall $(n=884)$ & Atopy $(n=603)$ & No Atopy $(n=262)$ \\
\hline Pampas de San Juan & $1.18(1.02$ to 1.38$)$ & $1.18(0.985$ to 1.42$)$ & $1.07(0.806$ to 1.43$)$ \\
Villa El Salvador & $\mathrm{p}=0.03$ & $\mathrm{p}=0.07$ & $\mathrm{p}=0.63$ \\
& $0.954(0.867$ to 1.05$)$ & $0.925(0.829$ to 1.03$)$ & $1.06(0.86$ to 1.32$)$ \\
& $\mathrm{p}=0.33$ & $\mathrm{p}=0.16$ & $\mathrm{p}=0.59$ \\
\hline
\end{tabular}

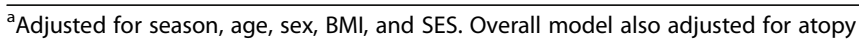




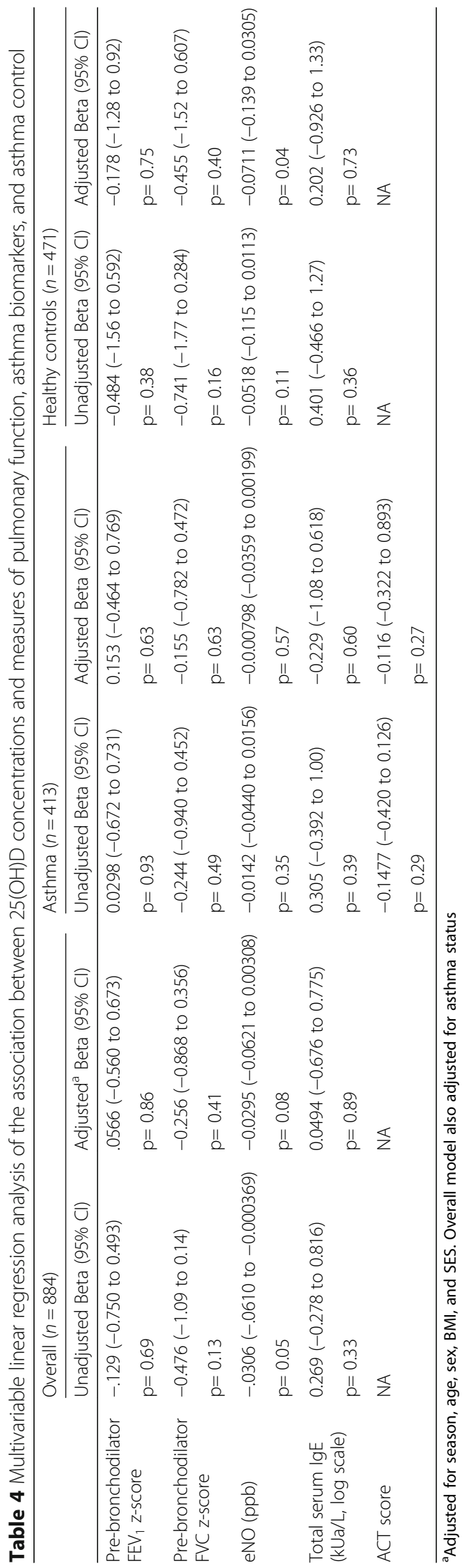


leading to different levels of sun exposure, which may help explain the difference in the prevalence of deficiency. A higher proportion of the population of Pampas is composed of primarily highland migrants, with $81 \%$ of participants in Pampas vs. $48 \%$ in Villa $(p<0.001)$ reporting one or both parents being born outside of Lima. This difference indicates that a much higher proportion of children in Pampas were born of first generation rural-to-urban migrant parents. Thus, there may be genetic differences between the two populations that could modulate the relationship between vitamin D deficiency and asthma. Indeed, polymorphisms in several genes related to vitamin D's function in the body can impact vitamin D status [17, 18], and there is evidence that variants in genes related to vitamin D status are associated with ancestry $[19,20]$.

Our findings suggest a U-or L-shaped ecological relationship between vitamin $\mathrm{D}$ deficiency and asthma prevalence, and a possible threshold effect for the protective benefit of vitamin $\mathrm{D}$ above concentrations occurring at approximately $27.5 \mathrm{ng} / \mathrm{ml}$. Other studies have observed similar relationships between 25(OH)D levels and asthma outcomes. A study of 264 preschool children demonstrated a threshold effect for 25(OH)D levels and asthma exacerbations at $20 \mathrm{ng} / \mathrm{ml}$ [21]. Other studies have demonstrated a U-shaped relationship of $25(\mathrm{OH}) \mathrm{D}$ levels with allergic sensitization [22], serum IgE levels [23], and pulmonary function $[24,25]$. There is a lack of consensus regarding optimal levels of circulating $25(\mathrm{OH}) \mathrm{D}$ concentrations for health outcomes related to the nonclassical functions of vitamin D. However, the threshold observed in this study should be considered exploratory. The distributions of $25(\mathrm{OH}) \mathrm{D}$ levels between the two communities have little overlap; thus, the different relationship under and above the threshold may in fact be driven by underlying differences between the two community populations, such as genetic or lifestyle differences. Furthermore, in Pampas, blood draws for children with asthma and controls were not conducted in parallel, and we were thus unable to adjust by month, which could have resulted in residual confounding. However, all blood draws in Pampas were conducted during the same season. In Villa, blood draws for cases and controls were conducted in parallel.

We did not find evidence for an association between 25(OH)D concentrations and ACT score or measures of pulmonary function. Our results differ from a study by Gupta et al. [26], which found a positive relationship of $25(\mathrm{OH}) \mathrm{D}$ serum concentrations with pulmonary function and ACT score among children with asthma. Cremers et al. [27] found no association between maternal vitamin $\mathrm{D}$ intake and lung function in offspring at age 6-7 years. However, in a study of 1213 Canadian children, Niruban (2014) found a U-shaped relationship between children's 25(OH)D levels and measures of pulmonary function $\left(\mathrm{FEV}_{1}\right.$ and $\left.\mathrm{FVC}\right)$, with children in low and high vitamin $\mathrm{D}$ categories having a reduced rate of change in lung function [25].

Our results also do not provide evidence for a relationship between 25(OH)D levels and FeNO. Fractional exhaled nitric oxide (FeNO) is a marker of lung inflammation and is known to be elevated in individuals with asthma [28]. Our results regarding FeNO are consistent with a study conducted by our group showing no association between 25(OH)D levels and FeNO [7, 29-31]. Our results also do not support an association between $25(\mathrm{OH}) \mathrm{D}$ concentrations and total serum IgE. The literature regarding vitamin $\mathrm{D}$ deficiency and markers of allergy has been mixed [6]. In a cohort of 616 Costa Rican children, total serum IgE and 25(OH)D were inversely associated [32]. Conversely, one study of 7288 British adults demonstrated a U-shaped relationship between 25(OH)D and total serum IgE; elevated serum IgE was associated with both low and high $25(\mathrm{OH}) \mathrm{D}$ concentrations [23]. In a study conducted by our group in Peru, we did not observe an association between IgE and total 25(OH)D levels [7], consistent with current findings. Well-designed, prospective studies and supplementation trials are needed to clarify the relationship between vitamin $\mathrm{D}$ deficiency and allergy.

There are limitations to this study. We did not adjust for genetic factors associated with vitamin D deficiency and asthma risk, and lifestyle factors, such as general dietary factors, sun exposure, and physical activity levels are not accounted for in our analyses. Of note, the study population had negligible reported use $(<5 \%)$ of inhaled corticosteroids, virtually eliminating corticosteroid use as a confounder. In addition, a higher percentage of children without asthma had their blood drawn during the fall season as compared to summer, which could have led to a conservative bias and may help explain our observing no association between asthma and 25(OH)D concentrations in Villa El Salvador. Our definition of current asthma, based on the presence of wheeze or medication use in the prior 12 months, could have led to the inclusion of non-asthma cases in the asthma group. However, $92.3 \%$ of children with current asthma also had a previous physician diagnosis, indicating that misclassification was likely minimal in our study population. Another limitation of this study is the lack of information regarding sun exposure levels, which could have acted as confounding factor in our analyses.

An important limitation of cross-sectional studies is the inability to assess temporality or causality. For this reason, well-designed, large-scale randomized controlled supplementation trials are needed to clarify the relationship between vitamin D deficiency and asthma and allergy, particularly the effect of maternal supplementation on disease risk in offspring. Studies examining exposures 
beyond 4 years of age may be missing the critical window of exposure for determining risk in later life, since the prenatal period and the first 1000 days of life are hypothesized to be etiologically relevant for determining asthma and allergy risk [33]. There is, however, significant evidence that vitamin D supplementation can improve asthma control and reduce of exacerbations. A recent Cochrane systematic review and meta-analysis showed with high quality evidence that vitamin D supplementation significantly reduced the risk of asthma exacerbations requiring oral corticosteroids (rate ratio 0.63, 95\% CI: 0.45 to 0.88 ) [34]. The risk of hospitalization was also significantly reduced, although the evidence was of moderate quality [34]. Thus, vitamin D supplementation has the potential to play a role in asthma management, which, given the relative affordability and safety of vitamin D supplements, could have profound implications in low-resource settings.

This study enrolled a large sample of children. Furthermore, this study contributes important information regarding the prevalence of vitamin D deficiency in Latin American countries, which is decidedly lacking. Given that the selection criteria were minimal for our study and that we observed a wide range of $25(\mathrm{OH}) \mathrm{D}$ values, we believe our results to be generalizable to other pediatric populations, barring any relevant genetic differences.

\section{Conclusion}

The results of our study suggest that the relationship between $25(\mathrm{OH}) \mathrm{D}$ levels and asthma may be stronger among populations with a higher prevalence of deficiency, and among individuals with the allergic phenotype. Combined data from both study sites suggests that the relationship between 25(OH)D levels and asthma displays a threshold effect at approximately $27.5 \mathrm{ng} / \mathrm{ml}$. Our study does not support associations of total serum 25(OH)D concentrations with pulmonary function measures, asthma control, or markers of lung inflammation (FeNO) or allergy (IgE). There is a need for comprehensive birth cohort studies examining exposures in utero and early life, including nutritional factors such as vitamin D deficiency. Randomized controlled trials conducted in children to determine the effect of vitamin D supplementation on incident asthma and asthma severity and control are also needed.

\section{Additional file}

Additional file 1: Table S1. Online Supplement: Results of sensitivity analyses; Description of data: Results of sensitivity analyses for excluding children with previous asthma from main analyses. (PDF 92 kb)

\section{Abbreviations}

ACT: Asthma Control Test; BMl: Body Mass Index; FeNO: Fractional exhaled nitric oxide; $\mathrm{FEV}_{1}$ : Forced expiratory volume in 1 second; FVC: Forced vital capacity; IgE: Immunoglobulin E; SES: Socioeconomic status

\section{Acknowledgements}

We gratefully acknowledge Mr. Shawn Sweeten at the Nemours Children's Health System for his contribution to laboratory analyses, and the Peru Center for Asthma Research study team at the Asociación Benéfica PRISMA for their contributions. We also gratefully acknowledge Dr. Kerry Schulze for her advice on laboratory analyses, as well all other GASP Study Investigators for their contributions.

Other members of the GASP Study Investigators: Patrick Breysse PhD, D'Ann Williams DrPH, Caroline Johnson BS, Sonali Bose MD MPH, Lindsay Underhill MS, Rocío Galvez RD, Chen Chen MSPH.

\section{Funding}

This project was funded by a grant from the National Institute of Environmental Health Sciences, National Institutes of Health (R01ES018845, R01ES018845-S1) and Biomedical Research, Nemours Children's Health System. Suzanne Pollard was supported by a grant from the Fogarty International Center, Office of AIDS Research, National Cancer Center, National Heart, Blood, and Lung Institute, and the NIH Office of Research for Women's Health through the Fogarty Global Health Fellows Program Consortium comprised of the University of North Carolina, Johns Hopkins University, Morehouse School of Medicine, and Tulane University (5R25TW009340). William Checkley was supported by a Pathway to Independence Award (ROOHL096955) from the National Heart, Lung and Blood Institute, National Institutes of Health.

\section{Availability of data and materials}

The datasets generated and/or analyzed during the current study are available from the corresponding author on reasonable request.

\section{Authors' contributions}

SLP contributed to study design and study coordination, conducted statistical analyses, and drafted the manuscript. J $J$ contributed to study design, data analysis, and drafting of the manuscript. EM oversaw laboratory analyses of samples and contributed to data analysis, data interpretation, and drafting of the manuscript. KR, CTM, KT, and GMG contributed to study coordination, laboratory analyses, and critical review of manuscript. NNH and WCH lead the study design and conduct, and contributed to data analysis and manuscript writing. All authors approved the final manuscript. SLP and WCH had full access to all the data in the study and take responsibility for the integrity of the data and the accuracy of the data analysis.

\section{Competing interests}

The authors declare that they have no competing interests.

\section{Consent for publication}

There is no individually identifiable data presented in this manuscript.

\section{Ethics approval and consent to participate}

The Institutional Review Boards at the Johns Hopkins University School of Medicine, Baltimore, USA, and A.B. PRISMA in Lima, Peru approved this study. All participants provided written informed consent or assent.

\section{Publisher's Note}

Springer Nature remains neutral with regard to jurisdictional claims in published maps and institutional affiliations.

\section{Author details \\ ${ }^{1}$ Division of Pulmonary and Critical Care, School of Medicine, Johns Hopkins University, 1800 Orleans Ave, Suite 9121, Baltimore, USA. ${ }^{2}$ Department of International Health, Bloomberg School of Public Health, Johns Hopkins University, Baltimore, USA. ${ }^{3}$ Center for Pharmacogenomics and Translational Research, Nemours Children's Health System, Jacksonville, FL, USA. \\ ${ }^{4}$ Biomedical Research Unit, A.B. PRISMA, Lima, Peru.}

Received: 20 December 2016 Accepted: 23 May 2017

Published online: 02 June 2017

\section{References}

1. Network GA. The Global Asthma Report 2014. Auckland: Global Asthma Network; 2014. http://www.globalasthmareport.org/resources/Global_ Asthma_Report_2014.pdf. 
2. Kerley $C P$, et al. Vitamin $D$ as an adjunctive therapy in asthma. Part 1: A review of potential mechanisms. Pulm Pharmacol Ther. 2015;32:60-74.

3. Adams JS, Hewison M. Regulation of Innate and Adaptive Immunity. Diabetes. 2009:4:80-90.

4. Ho S-M. Environmental epigenetics of asthma: an update. J Allergy Clin Immunol. 2010;126:453-65.

5. Wu AC, et al. Effect of vitamin D and inhaled corticosteroid treatment on lung function in children. Am J Respir Crit Care Med. 2012;186:508-13.

6. Kerley $C P$, et al. Vitamin D as an adjunctive therapy in asthma. Part 2: A review of human studies. Pulm Pharmacol Ther. 2015;32:75-92.

7. Checkley W, Robinson CL, Baumann LM, Hansel NN, Romero KM, Pollard SL, Wise RA, Gilman RH, Mougey E, Lima JJ, PURA Study Investigators. Clin Exp Allergy. 2015;45(1):273-82.

8. Robinson $\mathrm{CL}$, et al. Effect of urbanisation on asthma, allergy and airways inflammation in a developing country setting. Thorax. 2011;66(12):1051-7.

9. Program NAEaP. Expert Panel Report 3: Guidelines for the Diagnosis and Management of Asthma Full Report 2007. 2007.

10. Miller MR, et al. Standardisation of spirometry. Eur Respir J. 2005;26:319-38.

11. Quanjer PH, et al. Multi-ethnic reference values for spirometry for the 3-95-yr age range: the global lung function 2012 equations. Eur Respir J. 2012;40(6):1324-43.

12. Nathan RA, et al. Development of the asthma control test: a survey for assessing asthma control. J Allergy Clin Immunol. 2004;113:59-65.

13. Schatz $M$, et al. The minimally important difference of the Asthma Control Test. J Allergy Clin Immunol. 2009;124(4):719-23.e1.

14. Schatz M, et al. Asthma Control Test: reliability, validity, and responsiveness in patients not previously followed by asthma specialists. J Allergy Clin Immunol. 2006;117(3):549-56.

15. de Onis $\mathrm{M}$, et al. Development of a WHO growth reference for school-aged children and adolescents. Bull World Health Organ. 2007;85(9):660-7.

16. Holick MF. Vitamin D status: measurement, interpretation, and clinical application. Ann Epidemiol. 2009;19:73-8

17. Saccone $D$, Asani F, Bornman $L$. Regulation of the vitamin $D$ receptor gene by environment, genetics and epigenetics. Gene. 2015;561:171-80.

18. Li F, et al. Vitamin D deficiency is associated with decreased lung function in Chinese adults with asthma. Respiration. 2011;81:469-75.

19. Carpenter TO, et al. Vitamin D binding protein is a key determinant of 25-hydroxyvitamin D levels in infants and toddlers. J Bone Miner Res. 2013;28:213-21.

20. Batai $K$, et al. Common vitamin D pathway gene variants reveal contrasting effects on serum vitamin D levels in African Americans and European Americans. Hum Genet. 2014;133:1395-405.

21. Beigelman $A$, et al. The association between vitamin $D$ status and the rate of exacerbations requiring oral corticosteroids in preschool children with recurrent wheezing. J Allergy Clin Immunol. 2014;133(5):1489-92. 1492.e1-3.

22. Rothers J, et al. Cord blood 25-hydroxyvitamin D levels are associated with aeroallergen sensitization in children from Tucson, Arizona. J Allergy Clin Immunol. 2011;128(5):1093-9.e1-5.

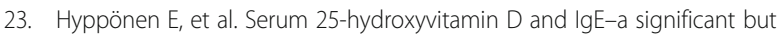
nonlinear relationship. Allergy. 2009:64:613-20.

24. Thuesen $\mathrm{BH}$, et al. The association of serum $25-\mathrm{OH}$ vitamin $\mathrm{D}$ with atopy, asthma, and lung function in a prospective study of Danish adults. Clin Exp Allergy. 2015;45:265-72.

25. Niruban SJ, Alagiakrishnan K, Beach J, Senthilselvan A. Association of vitamin D with respiratory outcomes in Canadian children. Euro J Clin Nutr. 2014;68:1334-0.

26. Gupta A, et al. Relationship between serum vitamin D, disease severity, and airway remodeling in children with asthma. Am J Respir Crit Care Med. 2011;184:1342-9.

27. Cremers E, et al. Maternal and child's vitamin D supplement use and vitamin D level in relation to childhood lung function: the KOALA Birth Cohort Study. Thorax. 2011;66:474-80

28. Birrell MA, et al. Utility of exhaled nitric oxide as a noninvasive biomarker of lung inflammation in a disease model. Eur Respir J. 2006;28(6):1236-44.

29. Yao T-C, et al. Serum 25-hydroxyvitamin D levels in relation to lung function and exhaled nitric oxide in children. J Pediatr. 2014;165:1098-1103.e1.

30. Goldring ST, et al. Prenatal vitamin d supplementation and child respiratory health: a randomised controlled trial. PLoS One. 2013;8:e66627.

31. Pike $\mathrm{KC}$, et al. Maternal late-pregnancy serum 25-hydroxyvitamin D in relation to childhood wheeze and atopic outcomes. Thorax. 2012;67:950-6.
32. Brehm JM, et al. Serum vitamin D levels and markers of severity of childhood asthma in Costa Rica. Am J Respir Crit Care Med. 2009;179:765-71.

33. Wegienka G, Zoratti E, Johnson CC. The role of the early-life environment in the development of allergic disease. Immunol Allergy Clin N Am. 2015:35:1-17.

34. Martineau AR, et al. Vitamin D for the management of asthma. Cochrane Database Syst Rev. 2016;9:CD011511.

\section{Submit your next manuscript to BioMed Central and we will help you at every step:}

- We accept pre-submission inquiries

- Our selector tool helps you to find the most relevant journal

- We provide round the clock customer support

- Convenient online submission

- Thorough peer review

- Inclusion in PubMed and all major indexing services

- Maximum visibility for your research

Submit your manuscript at www.biomedcentral.com/submit
Biomed Central 